\title{
Early Adopters to Early Majority - What's Driving the Artificial Intelligence and Machine Learning Powered Transformation in Financial Services?
}

\author{
Srikrishna Chintalapati ${ }^{1}$ \\ ${ }^{1}$ Department of Marketing and Strategy, Indian Institute of Management- Rohtak, City Southern Bypass, Sunaria, \\ Rohtak, India \\ Correspondence: Srikrishna Chintalapati, Department of Marketing and Strategy, Indian Institute of Management- \\ Rohtak, City Southern Bypass, Sunaria, Rohtak, Haryana 124010, India.
}

Received: January 17, 2021

Accepted: February 17, 2021

Online Published: March 18, 2021

doi:10.5430/ijfr.v12n4p43

URL: https://doi.org/10.5430/ijfr.v12n4p43

\begin{abstract}
From retail banking to corporate banking, from property and casualty to personal lines, and from portfolio management to trade processing, the next wave of digital disruption in financial services has been unleashed by the concepts and applications of Artificial Intelligence (AI) and Machine Learning (ML). Together, AI and ML are undoubtedly creating one of the largest technological transformations the world has ever witnessed. Within the advanced streams of research in $\mathrm{AI}$ and ML, human intelligence blended with the cognitive reasoning of machines is finally out of the labs and into real-time applications. The Financial Services sector is one of the early adopters of this revolution and arguably much ahead of its leverage compared to other sectors. Built on the conceptual foundations of Innovation diffusion, and a contemporary perspective of enterprise customer life-cycle journey across the AI-value chain defined by McKinsey Global Institute (2017), the current study attempts to highlight the features and use-cases of early-adopters of this transformation. With the theoretical underpinning of technology adoption lifecycle, this paper is an earnest attempt to comment on how AI and ML have been significantly transforming the Financial Services market space from the lens of a domain practitioner. The findings of this study would be of particular relevance to the subject matter experts, Industry analysts, academicians, and researchers focussed on studying the impact of AI and ML in the financial services industry.
\end{abstract}

Keywords: artificial intelligence, machine learning, financial services, banking, insurance, capital markets, digital transformation

\section{Introduction and Research Questions}

Studies have revealed that with a projected overall spend of $\$$ 58Bn by 2021 (Soni et al., 2019) and 4.6 folds increase in the deal volumes (Deloitte, 2017), and a 300\% increase in external investments (Huimin Lu, Yujie Li , Min Chen, Hyoungseop Kim, 2018)- AI is present and prevalent in today's world. One of the common and largest implications of $\mathrm{AI}$ and ML's influence on business is making interactions with machines smarter and more intelligent (Copeland, 2020; Deloitte Insights, 2019). There has been sizable variance amongst the adoption patterns of the AI and ML-powered transformation across different sectors. The financial services (FS) sector in specific, one of the early adopters and aggressive investors of AI and ML systems (Mazzotta \& Chakravorti, 2014) has been realizing the tangible benefits of this transformation. The benefits range from transforming customer experience to creating a more efficient back-office, ensuring regulatory compliance to augmenting the human workforce with timely and relevant actionable insights, and up to helping the enterprises create innovation by enabling a faster go-to-market of new products and solutions (Go et al., 2020).

However, the literature review proves that this area has been the hotspot of research focus, as studies indicate the number of articles inspecting the impact of AI on Business Outcomes has almost grown six times between 2013-2016 (PC Evans, 2016). A study by Accenture, (2016) predicts that over a dozen developed nations are capable of experiencing double digit economic growth by considering $\mathrm{AI}$ as a key decisive factor of production. Currently, in the FS industry, the AI and ML deployment has matured to encircle the core functions of the business, such as the 
decisions that can influence the strategic priorities, competitive landscape and transform the business value chain and drive profitability, scalability, and sustainability.

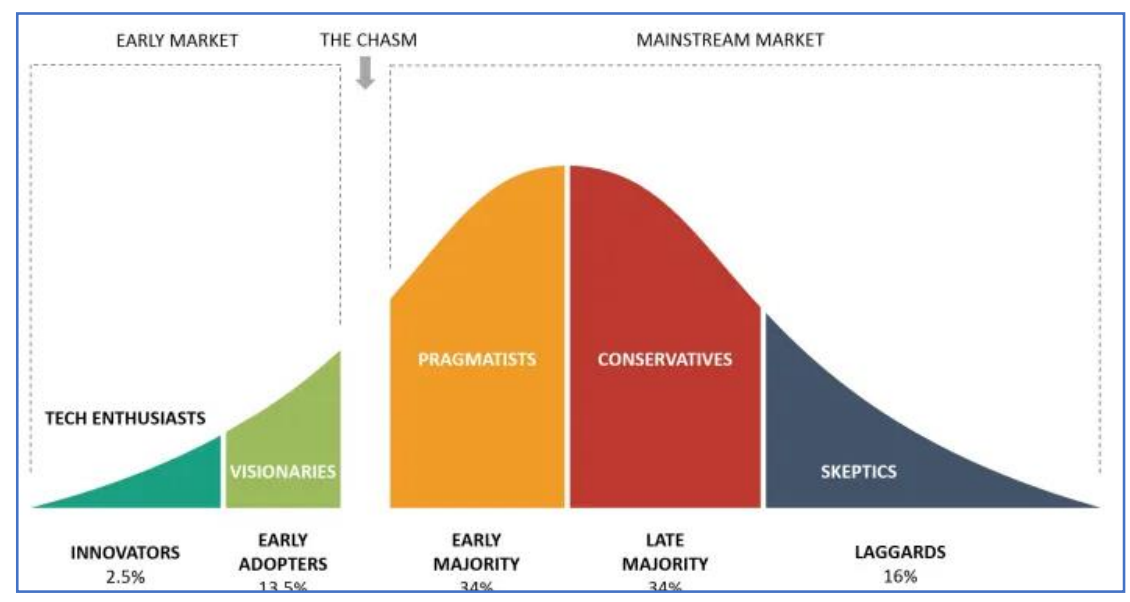

Figure 1. Crossing the chasm, technology adoption life cycle model

The current study focussed on the widely known and accepted practitioner definitions of 'Early adopters' and 'Early majority' from the extant research. A renowned scholar and sociologist Everett M Rogers in his book Diffusion of Innovations (Rogers, 2010), presented a seminal definition of these two most referred and researched personas of Innovation adopters in any social system of innovation based on the psychographic profiling of the potential buyers. The model is widely referred to and studied in the pretext of "Technology Adoption Life-cycle" by contemporary researchers. The study of Innovation Diffusion by Everett M Rogers (2010) has been further elucidated by Jeoffrey Moore in his book "Crossing the Chasm" (Moore \& McKenna, 1999) that believed to have helped the technology researchers and marketers channelize their thinking and efforts towards advancing an innovation/product in the Technology Innovation life-cycle. With this theoretical underpinning, it is important to assimilate two critical definitions that are relevant in the current study 1) Early adopters 2) Early majority

Early Adopters: Also known as visionaries, the set of buyers that buy into a new product/innovation very early in its life cycle despite the absence of a credible review mechanism. They believed to make buying decisions based on their intuitions and vision. Unlike the most advanced group of buyers (innovators), Early Adopters are not technocrats, may not always possess the technical attainment to make an informed decision. They are visionaries that see a futuristic opportunity and take the risk of trying something new.

Early Majority: Also known as Pragmatists, as the name suggests, are the considerably large psychographic segment of buyers that make a buying decision based on credible references and success stories. Although they do share some attributes of the Early adopters, they are driven by a more pragmatic/practical approach towards innovation diffusion. Crossing the chasm (Moore \& McKenna, 1999) between the early adopters to the early majority and advancing to the latter is considered to be a significant breakthrough in any product/Innovation life-cycle.

\section{Research Questions}

The study attempts to evaluate three critical research questions to understand the impact of AIL and ML in the research context of Financial Services.

1. What are the key strategic, regulatory, and tactical implications of the AI and ML landscape across the three micro-verticals (Banking, Insurance, and Capital Markets) of the financial services domain?

2. What are the prevalent applications and use-cases of AI and ML across the functional themes of the financial services market space?

3. How can the financial services sector harness this digital transformation for the better?

McKinsey \& Co, Executive guide to AI (McKinseyAnalytics, 2018) defines AI as "the ability of a machine to perform cognitive functions that are associated with human intelligence", AI is generally defined by the world researchers and 
practitioners as a combined application of four of the modern and advanced computational technologies, such as 1) Natural language processing, 2) Cognitive computing, 3) Deep/continuous learning, and 4) Smart analytics.

Machine learning has been applied for the first time in 1959 by an IBM scientist, Arthur Samuel, in the context of a checker's game solution. Using an exclusive recursive algorithm entitled "Minimax", Arthur established that a machine can be programmed to, not only play the checkers game against a human mind but also can win. Machine learning is a critical phenomenon that augments the impact of Artificial Intelligence which occurs when the computing and inference parameters auto-modify each other with their continued exposure to data and analytical reasoning, without human interference.

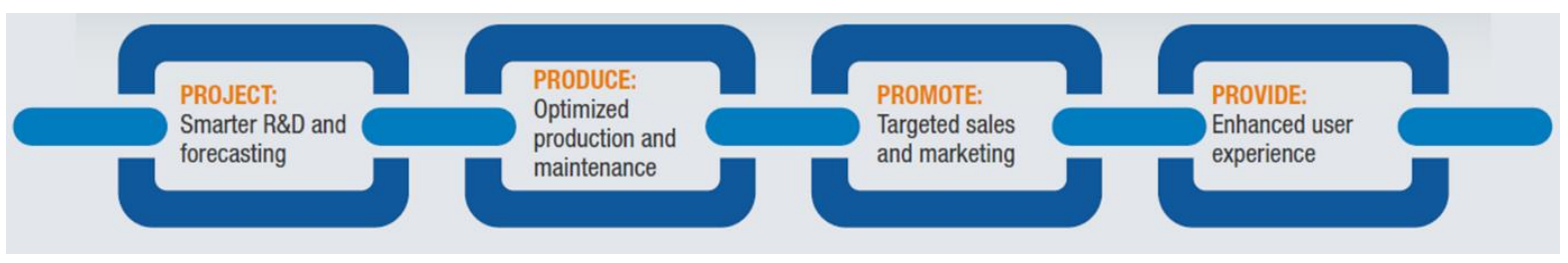

Figure 2. Four areas within the value chain where AI can create value (Source: McKinsey)

In the context of the current study, McKinsey's delineation of 'four areas within the value chain where AI can create value' (McKinsey, 2017) considered as the baseline theory appertaining to further elucidation and inferencing. The four areas outlined by McKinsey are- Project, Produce, Promote and Provide. Understandably, the four areas of the defined value chain can be correlated with the enterprise operational cycle of a financial services institute. Starting from forecasting and research and development (Project), to the actual optimized smart production (Produce) to package and promote it across the target universe (Promote) and finally build and extend superior customer experience (Provide). This framework by McKinsey, (2017) provides a strong credible conceptual foundation to appraise the adoption of AI and ML across the functional value chain of a financial institution. The current study is based on the lifecycle view of the customer journey across the enterprise presented as in the outlined study of McKinsey, (2017)

With the theoretical and conceptual understanding of Innovation Diffusion and Technology Adoption Lifecycle, In the subsequent sections, the study attempts to castigate the real-world applications of AI across all three micro-verticals of the financial services sector- Banking, Insurance, and Capital Markets (including both sell-side and buy-side) and proceeds to identify an early-adopter use case for each of the identified implication. The study further attempts to identify the early adopters of AI and ML in the Financial Services landscape along with the specific business problem they tried to address.

\subsection{Research Question-1}

What are the key strategic, regulatory, and tactical implications of the AI and ML landscape across the three micro-verticals (Banking, Insurance, and Capital Markets) of the Financial Services domain?

\subsubsection{AI and ML in Banking}

'Touted as the next major disruptor, AI is making inroads across the banking value chain. Although most banks are still in the early stages of AI adoption, immediate applications involve achieving productivity gains and developing proactive compliance/risk management systems. The magnitude of potential benefits, however, remains largely to be tapped- (Deloitte, 2018a)

The Human-first approach has been a fundamental philosophical cornerstone of the traditional banking experience. However, with AI and ML witnessing deeper penetration and started making decisions and inferences with lesser human involvement, the banking sector started to encounter incisive transformation of the business model over the years and continue to evolve. AI and ML have fundamentally empowered the banking customer with compelling user experience, competent and actionable insights, and comfort and convenience of operation. Some of the notable applications of AL and ML-powered banking approach can be listed as 1) Enhanced customer experience 2) Efficiency and convenience of banking 3) Stronger and structured risk management and regulatory compliance procedures 4) Smarter and more agile workflows for bank-end operations management 5) improved data analysis and Reasoning 6) Creation of new revenue models by adopting the next-gen technologies such as Robotic Process Automation (RPA), 
Chatbots, Conversational banking, Mobile and handheld banking 7) Smarter, easier and more secured Payment operations amongst the others.

With the emergence of AI and ML-powered banking applications as a critical differentiator, the global banking market space is now evidencing a never-before need to develop a strategic approach to incorporate AI and ML into their offerings catalogue to create a competitive advantage.

\subsubsection{AI and ML in Insurance}

'While there are several technologies that are being developed and employed to improve the experience and business of insurance in general, the potential that artificial intelligence (AI) and big data may play in insurance production is strong. There is much interest expressed from both the industry and regulators in how technology can benefit the insurance sector, especially given the potential of improving the customer experience'- OECD, (2020)

The insurance industry traditionally is lagging behind the other industries in exploring the benefits of AI. Technology disruption in the Industry is more evident in the contemporary world than before, Insurers are increasingly using AI for better for applications such as 1) New Product Development 2) Claims Management and Administration 3) User experience 4) Underwriting and Risk monitoring 4) Insurance Operations 5) Customer Servicing 6) Sales, marketing and distribution.

Also, there are several other functional applications in Insurance beginning to evolve or already made headway in using AI and ML to their benefit. Telematics, Automated Investment Advisory, Text analysis, and Natural language processing, and Recommender systems based on Sales data, Social media data (Kotras, 2020) are some of the use-cases akin to this evolution. Studies reveal that about one-third of European Insurance carriers use Machine Learning in their operations for more efficient and data-driven decision making (OECD, 2020)

\subsubsection{AI and ML in Capital Markets}

'Technological innovation will disrupt capital markets participants' competitive advantages. Harnessing big data will be paramount to remain competitive in the capital. Technology risk shifts from managing operational and implementation failures to controlling cyber risk'- PwC, (2020).

Modern technologies at the forefront of this transformation in the Capital Markets Industry, there is a multitude of opportunities across the industry value chain. Right from Investment and wealth management to the trade processing and back-office and up to the market infrastructure, the technology revolution is expected to be front-lined by AI and ML whereas, although a bit far-sighted, disruption seems inevitable with the evolution of distributed ledger (blockchain) (Lee, 2018). Efficiency, enhanced security, analytical reasoning, and seamless performance will foster the adoption of AI and ML in the Capital Markets Industry (Mendelsohn, 1995).

By incorporating AI and ML-powered reasoning deeply into their business strategies the global capital market majors are already evincing considerable business value of this technology proliferation 1) Financial models have become more data and insight-driven and hence accurate 2) Automated Investment Advisory that is more driven by the data and trends and less of human intuition 3) Automated reporting, integrated workflow, and administration of the market infrastructure 4) faster and responsive deal experience 5) Predictive modeling- Pre and Post-trade, Risk 6) Digital disruption in sales and service. (Accenture, 2018a)

\subsection{Research Question-2}

What are the prevalent applications and use-cases of AI and ML across the functional themes of the Financial Services market space?

This report attempts to outline some of the most popular and early adopter use-cases of AL in ML Adoption in the Banking, Financial Services, and Insurance Industry, in correlation with McKinsey's (2017) framework of value creation by AI: 
Table 1. Live and current use-cases of AI in ML in banking

\begin{tabular}{|c|c|c|}
\hline Stage in the value-chain & Real-world Implication of AI & 'Early Adopter' Use-case \\
\hline $\begin{array}{l}\text { Project (Smarter R\&D and } \\
\text { Forecasting) }\end{array}$ & Data analysis and Insights & $\begin{array}{l}\text { Avaloq (Artificial Intelligence, Data, and } \\
\text { Insights for Banking) }\end{array}$ \\
\hline \multirow{3}{*}{$\begin{array}{l}\text { Produce (Optimized } \\
\text { production and } \\
\text { maintenance) }\end{array}$} & Deposits and lending & $\begin{array}{l}\text { Upstart (Automated business and Personal } \\
\text { Loans) }\end{array}$ \\
\hline & AML/KYC & $\begin{array}{l}\text { United Overseas Bank, Tookitaki and } \\
\text { Deloitte (Machine learning pilot for AML } \\
\text { prevention) }\end{array}$ \\
\hline & Payments/ Digital Wallets & $\begin{array}{l}\text { Pelican.AI (Intelligent Payments and } \\
\text { compliance platform) }\end{array}$ \\
\hline \multirow[t]{2}{*}{$\begin{array}{l}\text { Promote (Targeted sales } \\
\text { and marketing) }\end{array}$} & Digital Marketing/Campaigning & $\begin{array}{l}\text { Adobe Analytics } \text { and Adobe } \\
\text { (Digital marketing } \\
\text { banking) }\end{array}$ \\
\hline & Personalized targeting & Temenos Intensify (Real-time campaigns) \\
\hline \multirow[t]{2}{*}{$\begin{array}{l}\text { Provide - (Enhanced user } \\
\text { Experience) }\end{array}$} & Conversational AI- Chatbots & $\begin{array}{l}\text { AMELIA (Conversational AI Chatbot for } \\
\text { Digital Banking) }\end{array}$ \\
\hline & Customer Engagement & $\begin{array}{l}\text { Royal Bank of Scotland and Pega } \\
\text { (one-to-one, personalized conversations } \\
\text { for } 17 \text { Million customers) }\end{array}$ \\
\hline
\end{tabular}

Table 2. Live and current use-cases of $\mathrm{AI}$ and $\mathrm{ML}$ in insurance

\begin{tabular}{|c|c|c|}
\hline Stage in the value-chain & Real-world Implication of AI & 'Early Adopter' Use-case \\
\hline \multirow{2}{*}{$\begin{array}{l}\text { Project (Smarter R\&D and } \\
\text { Forecasting) }\end{array}$} & Risk Monitoring & Cytora (AI-Powered Risk monitoring) \\
\hline & New product development & $\begin{array}{l}\text { Celina Insurance Group } \\
\text { learning Solution for risk selection, } \\
\text { pricing, and customer retention) }\end{array}$ \\
\hline \multirow{3}{*}{$\begin{array}{l}\text { Produce (Optimized } \\
\text { production and } \\
\text { maintenance) }\end{array}$} & Underwriting & $\begin{array}{ll}\text { Acturis underwriting } & \text { (Insurance } \\
\text { Software-as-a-product) } & \end{array}$ \\
\hline & Claims Management & $\begin{array}{l}\text { Manulife -Canada (Virtual guidance on } \\
\text { Claims processing) }\end{array}$ \\
\hline & Risk Monitoring & $\begin{array}{l}\text { Cropin SmartRisk (AI and ML-powered } \\
\text { Risk monitoring, Forecasting solution for } \\
\text { Agri-Insurance) }\end{array}$ \\
\hline \multirow[t]{3}{*}{$\begin{array}{l}\text { Promote (Targeted sales } \\
\text { and marketing) }\end{array}$} & Distribution & $\begin{array}{l}\text { Insurify.com (Streamlined } \\
\text { Insurance marketplace) }\end{array}$ \\
\hline & Focused targeting & Allstate (chatbot system for sales agents) \\
\hline & Recommender Systems & $\begin{array}{l}\text { MS\&AD AutoML } 2.0 \quad \text { (Policy } \\
\text { recommendations system powered by AI) }\end{array}$ \\
\hline \multirow[t]{2}{*}{$\begin{array}{l}\text { Provide - (Enhanced user } \\
\text { Experience) }\end{array}$} & Agent/User experience & $\begin{array}{l}\text { Met Life/The wall: (Data aggregation into } \\
\text { the single interface) }\end{array}$ \\
\hline & Client Servicing & USAA (Virtual customer service agent) \\
\hline
\end{tabular}


Table 3. Live and current use-cases of AI and ML in capital markets

\begin{tabular}{|c|c|c|}
\hline Stage in the value-chain & Real-world Implication of AI & 'Early Adopter' Use-case \\
\hline \multirow[t]{2}{*}{$\begin{array}{l}\text { Project (Smarter R\&D and } \\
\text { Forecasting) }\end{array}$} & $\begin{array}{l}\text { Predictive Modelling (pre and } \\
\text { Post Trade) }\end{array}$ & $\begin{array}{l}\text { DTCC (Pre-trade and post-trade impact } \\
\text { analysis powered by AI) }\end{array}$ \\
\hline & Risk Exposure Monitoring & $\begin{array}{l}\text { Credit Suisse and Palantir (Solution to } \\
\text { monitor irregular trading behaviour) }\end{array}$ \\
\hline \multirow{3}{*}{$\begin{array}{l}\text { Produce (Optimized } \\
\text { production and } \\
\text { maintenance) }\end{array}$} & Automated Reporting & $\begin{array}{l}\text { Financial Conduct Authority (Automated } \\
\text { Regulatory reporting powered by AI) }\end{array}$ \\
\hline & Trade processing Efficiency & $\begin{array}{l}\text { JP Morgan (AI-enabled prediction of } \\
\text { Trade price impact and cost) }\end{array}$ \\
\hline & Regulatory Reporting & $\begin{array}{llll}\text { Wolters Kluwer } & \text { and } \begin{array}{r}\text { PWC } \\
\text { (Proof-of-concept } \\
\text { Reporting) }\end{array} & & \\
\end{array}$ \\
\hline \multirow[t]{3}{*}{$\begin{array}{l}\text { Promote (Targeted sales } \\
\text { and marketing) }\end{array}$} & $\begin{array}{lll}\text { Digital enabled } & \text { Investment } \\
\text { Services } & & \\
\end{array}$ & $\begin{array}{l}\text { Onfido (Identity verification through } \\
\text { Image recognition) }\end{array}$ \\
\hline & Automated targeting & $\begin{array}{l}\text { Goldman Sachs Persado (AI-powered } \\
\text { automated copywriting and marketing) }\end{array}$ \\
\hline & $\begin{array}{lll}\text { DataOps for } & \text { Wealth } \\
\text { Management } & & \\
\end{array}$ & $\begin{array}{l}\text { Kognetics (Machine Learning for Mergers } \\
\text { \&Acquisitions analysis) }\end{array}$ \\
\hline \multirow[t]{2}{*}{$\begin{array}{l}\text { Provide - (Enhanced user } \\
\text { Experience) }\end{array}$} & Automated Investment Advisory & $\begin{array}{l}\text { Betterment (First ever Robo advisor in the } \\
\text { US) }\end{array}$ \\
\hline & Client user experience & $\begin{array}{lll}\text { Wealthfront } & \text { (Personalized } & \text { onboarding } \\
\text { experience) } & & \end{array}$ \\
\hline
\end{tabular}

\subsection{Research Question-3}

How can the Financial Services sector harness this digital transformation for the better?

The current state of adoption of AI and ML across enterprises stands at a critical inflection point, where opportunity and uncertainty co-exist. The investments in this area are set to increase at an exponential scale, however about $41 \%$ of the enterprises are still unclear about the benefits of AI adoption (McKinsey, 2017). The largest share of the investment in AI is estimated to be on Machine learning as a critical enablement technology and $90 \%$ of the overall investment in $\mathrm{AI}$ is expected to be on Research \& Development. As the Financial Services sector being more aggressive of the pack, the AI-related investments are, correlating with the 48\% cross-sector CAGR, expected to reach $\$ 10$ Bn by 2021 (Deloitte, 2017, 2018b), more interestingly 76\% of the Banking CXOs believes that AI adoption will help them create a unique competitive differentiation (Deloitte, 2018b). AI and ML adoption in the Financial Services sector is slated to offer exponential growth and extensive opportunities for expansion. Some of them can be outlined as follows:

- A digital native enterprise with a proactive strategy for AI and ML adoption, that combines its digital prowess with seamless adoption and implementation of $\mathrm{AI}$ and $\mathrm{ML}$ is poised to create a strong market differentiator and outshine the competition

- $\mathrm{AI}$ and ML adoption is set to transform the traditional framework of pricing strategy, AI and ML-powered applications will create a strong differentiation that ultimately fosters customer engagement and affinity

- Across AI and ML dominant analytical and reasoning functions such as Anti Money Laundering (AML) and Know Your Customer (KYC) more promise is evident in identifying the false-positives and false-negatives that ultimately leads to operational efficiency

- Personal Finance Management (PFM) and Open API driven approach to customer communication and servicing creates a strong room for extreme automation and accelerated adoption of customer's financial agenda that ultimately helps to streamline customer's financial behaviour

- Using AI and ML, the financial institutions (FIs) automate some of the mundane, human-error prone processes such as data entry, data gathering, verification and validation of the customer data, identifying and removing the errands, and duplicates and many other activities that result in improving the productivity of the overall process 
- Using the intelligence and accuracy of machine for the mundane initial tasks, after-handling of data such as alert handling, duplicate alerts, escalation rates, transparent production support can be processed with enhanced control and efficiency

- $\quad$ The impending need for AI adoption by way of industrializing the AI-powered back-end operations; financial institutes create tailored customer experiences for the end-customers which expedites the pace of the overall AI and ML adoption

- A collaborative open API approach fosters real-time data mining and analytical reasoning of the shared data sets thereby increasing the speed, accuracy, and performance of the AI and ML-powered financial applications

- Applications powered by AL and ML are programmed to take a periodic check of the financial parameters that are part of the regulatory reporting exercise. This helps to flag and highlight any deviations to the compliance rules immediately to the relevant stakeholders. Using AI and ML the financial institutes will not only be able to handle their regulatory requirements with increased control and transparency but also streamline the reporting procedures

- Increased customer loyalty and retention: Using analytical reasoning as an intervening phenomenon, FIs can focus on continuous improvement of product features and performance and optimized customer engagement with more relevant content results in superior customer experiences that lead to customer loyalty and retention (Sternberg et al., 2018)

- In the long run, AI and ML adoption bring in consolidation in the marketplace. Firms with synergies will choose to come together/amalgamate for better business outcomes. Niche players look to consolidate and strengthen their offerings and area of expertise, this will lead to reduced search effort and onboarding timelines of end customers

While Financial Services leading from the front in AI and ML adoption, several peripheral sectors are still lagging in the adoption, and an even lesser number of players, approximately 20\%, adopted at scale (McKinsey, 2017). The chasm/gap between the early adopters and the early majority of the enterprises that are yet to make headway into the adoption of AI and ML is ever increasing. Lack of relevant and promising use-cases about their specific nature of the business, looming uncertainty and ambiguity over the contextual relevance of an existent business case(s), uncertainty around the return-on-investment projections have emerged as a strong roadblock in the path to digital maturity fostered by AI and ML adoption. The following are some of the challenges experienced and enlisted by the qualifying early majority (Rogers, 2010), late majority, and the laggards of the adoption of AI and ML in the financial services:

- Reigning data privacy and regulatory guidelines: constantly evolving data privacy, portability, and consumption guidelines such as General Data Protection Regulation 2016/679 (GDPR) in Europe, California Consumer Privacy Act (CCPA) in the United States, pose a great challenge to the adoption of AI and ML in the FS Industry. The guidelines will restrict the relative ability of the FIs to move/consume customer data across the borders

- With the emergence of 'Data, as a single most powerful, influencing component in structured decision making; collecting and curating the most relevant, accurate data from the abundant and unstructured raw data is seemingly more critical than before

- Training requirements: In the financial services industry, owing to several client engagement scenarios, there is an imminent need for stimulatory training across a variety of models to achieve complete control of the domain function, which often is not too easy to be created or replicated//repurposed with the existing inventory/ resources

- With large chunks of unstructured data availability in the marketplace, it is extremely critical to choose an unbiased, representative, neutral dataset to train and replicate the predictive models. Identifying the right data source is extremely critical to the success of an AI and ML-based predictive model

- The tidal load of data being generated and supplied into an FI's database architectures and machine learning algorithm need to be protected by deploying strong a data security infrastructure to eliminate the risks of data leak or security breach

- Low predictability and replicability of a business case and ROI projections: Due to the diverse and versatile nature of the financial services sector, each business scenario is unique and significantly different from other. Therefore, it is extremely difficult to create a unified machine learning algorithm that can auto-learn merely from the data exposure

- An ever-present 'replace-augment' debate between the machine and human workforce: while it is true that some of the repetitive tasks get automated with and AI and ML transformation, and hence it is possible to release some manpower requirements in a specific scenario; a large majority of the workforce needs urgent reskilling to augment the power of $\mathrm{AI}$ and ML in the business process. The question has a much wider impact on the talent 
availability and the socio-political attractiveness of the respective geography of operation. This question demands more structured thinking and disciplined approach while AL and ML-powered transformation aims to catapult itself as the future business models of financial services

- Ethical considerations: Adoption of Al and ML calls for an inclusive and comprehensive reassessment of human resources and regulatory mandates and addresses the ethical uncertainties before the transformative adoption of $\mathrm{AI}$ and ML starts driving the business models.

\section{Conclusion}

As observed from the growing interest and opportunities outlined in this study, the adoption of AI and ML in the financial services industry is here to stay and disrupt the extant and the deep-rooted traditional business models. Several early adopters of AI and ML-driven transformation have already leveraged significant benefits and created a strong competitive differentiation for themselves. The gap between early-adopters and early-majority is also growing at an exponential pace. There are multiple antecedents of successful AI and ML lead transformation in any financial services institution- starting from data acquisition, analysis, technology adoption, and most importantly the cultural alignment. There is no shortcut for accelerated AI and ML adoption in a financial enterprise and at some point, the adoption of AI or ML for at least a part of the overall business process is inevitable in the current scenario. The Financial Services industry is extremely data and experience intensive is strategically positioned to harness this disruption that finally leads to increased efficiency and cost reductions. Customer experience in the financial services industry advancing at an ever-growing demand than before. In foreseeable future, AI and ML will not only become the digital foundations of the overall enterprise IT architecture but also emerge as a mainstream technology swarm, such as 'an inviolable CXO priority'. Financial enterprises need to start mapping their customer journeys to identify the potential use-cases of adoption of AI and ML or start replicating the proven successful use-cases of the other sector/enterprise. The pace and cadence in which Financial Institutions innovate, adapt, build, replicate and sustain momentum in the AI and ML-driven transformation value chain will ultimately define their emergence either as a digital predator or a digital pray (Forrester, n.d.).

\section{Limitations and Directions for Future Research}

The financial services industry is an extremely competitive, most dynamic, and constantly evolving marketspace. Artificial Intelligence, machine learning, and peripheral technological innovations are in continuous evolution too. There would be more and more live and promising use-cases are expected to come into the real-world every day. As more such disruptive innovations evolve into the niche functional streams of the financial services industry; the "early adopters' of today will be eventually replaced with smarter and intelligent innovators of tomorrow, this could be one of the potential limitations of this study.

Future research can focus on emulating more insightful data around the AI and ML intrusion in any/all of the three micro-verticals of financial services- Banking, Insurance, and Capital Markets. The researchers can dive deeper into the more and more functional streams within each micro-vertical, such as corporate/retail/Investment banking, property and casualty, life, health, pensions, and annuity Insurance, trade processing, and market infrastructure to wealth/asset management to name a few. Longitudinal studies around the futuristic propositions that are set to unleash the next level of disruption across the financial services industry such as Blockchain, Crypto Currencies, cybersecurity and fraud detection, etc ... are some of the strongest opportune areas to explore further insights. FinTech segment is yet another burgeoning field of study for world practitioners and academicians to explore and assess the implications of AI and ML disruption. Similarly, RegTech and InsureTech could offer strong potential for future research expansion in this domain.

\section{References}

Accenture. (2016). Why artificial intelligence is the future of growth, accenture, 2016. Retrieved from https://www.accenture.com/us-en/insight-artificial-intelligence-future-growth

Accenture. (2018a). Capital markets vision 2022.

Accenture. (2018b). The intelligent capital markets firm. Retrieved from https://www.accenture.com/_acnmedia/Accenture/Conversion-Assets/DotCom/Documents/Local/en-gb/PDF_3/ Accenture-Redefining-Capital-Markets-with-Artificial-Intelligence-UKI.pdf\#zoom=50

Arthur, L. S. (1959). Some studies in machine learning using the game of checkers.

Chui, M. (2017). Artificial intelligence the next digital frontier. McKinsey and Company Global Institute, 47, 3-6.

Copeland, B. J. (2020). Artificial intelligence: Definition, examples, and applications. Encyclopedia Britannica.

Deloitte Insights. (2019). Tech Trends 2019-Beyond the digital frontier. 
Deloitte. (2017). From mystery to mastery: Unlocking the business value of Artificial Intelligence in the insurance industry. In Deloitte Digital (Issue November). Retrieved from https://www2.deloitte.com/content/dam/Deloitte/ru/Documents/financial-services/artificial-intelligence-in-insur ance.pdf

Deloitte. (2018a). Artificial intelligence in banks.

Deloitte. (2018b). The New Physics of Financial Services- Understanding how artificial intelligence is transforming the financial ecosystem. In World Economic Forum (Issue August). Retrieved from http://www3.weforum.org/docs/WEF_New_Physics_of_Financial_Services.pdf

Donepudi, P. K. (2017). Machine Learning and Artificial Intelligence in Banking. Engineering.

Forrester. (2015). Digital predator or digital prey: Which will your business be by 2020 ?

Go, E. J., Moon, J., \& Kim, J. (2020). Analysis of the current and future of the artificial intelligence in financial industry with big data techniques. Global Business \& Finance Review (GBFR), 25(1), 102-117.

Kotras, B. (2020). Opinions that matter: the hybridization of opinion and reputation measurement in social media listening software. In Media, culture and society, 42(7-8). https://doi.org/10.1177/0163443720939427

Lee, J. (2018). Distributed ledger technologies (blockchain) in capital markets: risk and governance. SSRN 3180553.

Lu, H. M., Li, Y. J., Chen, M., \& Hyoungseop Kim, S. S. (2018). Brain Intelligence: Go Beyond Artificial Intelligence. Mobile Networks and Applications, 24(2), 371-379. https://doi.org/10.1007/s12540-018-0053-3

Mazzotta, B., \& Chakravorti, B. (2014). Who pays more to use cash?. Journal of Payments Strategy \& Systems, 8(1), 94-107.

McKinsey Analytics. (2018). An executive's guide to AI. Retrieved from https://www.mckinsey.com/business-functions/mckinsey

McKinsey. (2017). Artificial intelligence - the next digital fronitier?. Network Security, 2017(4). https://doi.org/10.1016/S1353-4858(17)30039-9

Mendelsohn, L. B. (1995). Artificial Intelligence in Capital Markets, Chapter 5: Global Trading Utilizing Neural Networks: A Synergistic Approach. Virtual Trading.

Moore, G. A., \& McKenna, R. (1999). Crossing the chasm.

OECD. (2020). The impact of big data and artificial intelligence (AI) in the insurance sector. Retrieved from www.oecd.org/finance/Impact-Big-Data-AI-in-the-Insurance-Sector.htm

PC Evans, A. G. (2016). The rise of the platform enterprise: A global survey.

PwC. (2020). Capital Markets 2020 Will it change for good?.

Rogers, E. M. (2010). Diffusion of innovations. Simon and Schuster.

Soni, N., Singh, N., Kapoor, A., \& Sharma, E. K. (2019). Impact of Artificial Intelligence on Businesses: from Research, Innovation, Market Deployment to Future Shifts in Business Models Emanualz for Electronic Students View project Science of Spirituality View project Impact of Artificial Intelligence on Busin, 1-38. Retrieved from https://www.researchgate.net/publication/332898261

Sternberg, F., Pedersen, K. H., Ryelund, N. K., Mukkamala, R. R., \& Vatrapu, R. (2018). Analysing customer engagement of Turkish airlines using big social data. 2018 IEEE International Congress on Big Data (BigData Congress), 74-81.

\section{Copyrights}

Copyright for this article is retained by the author(s), with first publication rights granted to the journal.

This is an open-access article distributed under the terms and conditions of the Creative Commons Attribution license (http://creativecommons.org/licenses/by/4.0/). 